\title{
Capitalismo dependente e cultura autocrática: contribuições para entender o Brasil contemporâneo
}

\author{
Morena Gomes Marques \\ Universidade Federal do Estado do Rio de Janeiro, Escola de \\ Serviço Social, Rio de Janeiro, RJ, Brasil (UNIRIO)
}

Capitalismo dependente e cultura autocrática: contribuições para entender o Brasil contemporâneo Resumo: A construção deste ensaio é motivada pela necessidade de compreender a natureza dos dilemas vislumbrados na atual conjuntura brasileira - uma economia apartada das necessidades internas, marcada pela restrição sistemática aos trabalhadores no acesso a direitos sociais fundamentais, e um poder de Estado impermeável às necessidades das amplas maiorias. Deste modo, objetiva-se realizar uma análise crítica do que denominamos por cultura autocrática a partir dos seus dois elementos constitutivos: a dependência e a reciclagem do período contrarrevolucionário. Por cultura autocrática compreendemos a expressão política da dependência, caracterizada pela permanente reciclagem do processo democrático, o qual se mantém voltado para anular o ímpeto das forças sociais de baixo e preservar tanto o atual padrão de acumulação do capital, como o autoprivilégio da classe dominante. Para realização deste estudo procedemos à pesquisa bibliográfica e documental; e optamos por ter como principais interlocutores acerca do tema os pensadores Florestan Fernandes (1976, 2008, 2009) e Ruy Mauro Marini (2011, 2012), por considerar imprescindível a produção de ambos acerca do fenômeno da dependência latino-americana.

Palavras-chave: Capitalismo dependente. Classes sociais. Cultura autocrática.

Dependent Capitalism and Autocratic Culture: Contributions to understanding contemporary Brazil Abstract: This essay is motivated by the need to understand the nature of the dilemmas seen in Brazil today - an economy adorned by internal needs, marked by the systematic restriction of workers to access fundamental social rights, and a state power that is impermeable to the needs of the broad majorities. The article conducts a critical analysis of what we call autocratic culture based on its two constitutive elements: dependence and a recycling of the counter-revolutionary period. We understand autocratic culture to be the political expression of dependence, characterized by the permanent recycling of the democratic process, which remains focused on annulling the impetus of the social forces from below and preserving both the current standard of capital accumulation, as well as the self-privilege of the dominant class. The study involved bibliographic and document research. Our main interlocutors to the theme were the thinkers Florestan Fernandes (1976, 2008, 2009) and Ruy Mauro Marini $(2011,2012)$, because we believe that their work is essential to the phenomenon of Latin American dependence.

Keywords: Dependent capitalism. Social classes. Autocratic culture.

Recebido em 14.06.2017. Aprovado em 05.09.2017. Revisado em 17.11.2017.

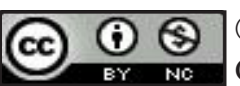

(C) O(s) Autor(es). 2018 Acesso Aberto Esta obra está licenciada sob os termos da Licença Creative Commons Atribuição-NãoComercial 4.0 Internacional (https://creativecommons.org/licenses/bync/4.0/deed.pt_BR), que permite copiar, distribuir e reproduzir em qualquer meio, bem como adaptar, transformar e criar a partir deste material, desde que para fins não comerciais, e que você forneça o devido crédito aos autores e a fonte, insira um link para a Licença Creative Commons e indique se mudanças foram feitas. 


\section{Introdução}

Frente a um cenário historicamente adverso, marcado pelo impeachment de uma presidenta democraticamente eleita, uma ofensiva conservadora à pobreza e um duro ajuste fiscal, este texto é motivado por uma razão simples: o esforço de compreender a realidade brasileira e, mais especificamente, a formação de uma democracia peculiar: residual no que tange ao consenso junto aos de baixo, mas extremamente generosa e manipulável no que diz respeito aos privilégios privados. Para tanto, objetiva-se proceder uma análise do que denominamos por cultura autocrática, enquanto fenômeno político simbiótico e prerrogativa necessária à dependência. Desta forma, este texto está estruturado em dois momentos: primeiro, um estudo acerca do conceito de dependência e superexploração da força de trabalho a partir de dois dos pensadores clássicos da tradição marxista brasileira: Florestan Fernandes (1976, 2008, 2009) e Ruy Mauro Marini (2011, 2012). A escolha por tais autores se dá pela valiosa produção intelectual empreendida por ambos sobre a formação social latino-americana, sua estrutura econômica e relação entre classes sociais. E, em segundo, a reflexão acerca da cultura autocrática a partir do que consideramos como os seus elementos estruturantes: a contemporaneidade da dependência, expressa no fenômeno de reprimarização da economia e no seu forte impulso agroexportador; e a reciclagem do período contrarrevolucionário.

Para a elaboração deste ensaio procedemos tanto uma revisão bibliográfica acerca do tema; como, no que diz respeito à contemporaneidade da dependência, além do estudo presente em Antunes (2008), Araújo (2011) e especialmente Osório (2012), utilizamos como fonte de dados o material produzido pela Associação de Comércio Exterior do Brasil (AEB) (2012).

\section{Dependência e superexploração da força de trabalho}

Segundo Prado Jr. (2011), todo povo detém em sua evolução um certo sentido. Este se observa não nos detalhes históricos, mas no conjunto dos fatos e acontecimentos essenciais que constituem essa evolução num largo período de tempo. O nosso sentido é heteronômico - envolve e confunde o novo e o arcaico - onde um "caráter mais estável, permanente, orgânico, de uma sociedade própria e definida, só se revela aos poucos, dominado e abafado que é pelo que o precede, e que continuará mantendo a primazia e ditando os traços essenciais na nossa evolução." (PRADO JÚNIOR, 2011, p. 29). Incorporadas as estruturas coloniais na ordem social competitiva, visualizou-se aqui uma emancipação política dissociada da autonomia econômica, expressa na ausência de um controle propriamente nacional do excedente econômico gerado pelo setor exportador, cuja consequência primeira foi a constituição de um mercado interno atrofiado, apartado das possibilidades de socialização dos recursos naturais para fins de integração nacional. Para Fernandes (2008, p. 53), a gênese de tais estruturas nos conduziu ao destino histórico inerente ao capitalismo dependente, o qual pode ser compreendido na formação de uma economia duplamente polarizada: de um lado, um setor de exportação de produtos primários, no qual se detêm, ao máximo, a dependência ao exterior; e de outro, um setor interno de produção, circulação e consumo de bens, ainda sujeito a fortes influxos externos.

Como bem afirmou Marini (2012, p. 47), "a história do subdesenvolvimento latino-americano é a história do desenvolvimento do sistema capitalista mundial" e, deste modo, a problemática das nações latinoamericanas nos impõe a análise da sua inserção enquanto parte subordinada e sócia-menor da divisão internacional do trabalho. No estabelecimento da ordem social competitiva, a função exercida pela América Latina esteve em sua capacidade de atender uma demanda mundial de alimentos e matérias-primas, cuja relevância cresceu em proporção direta ao desenvolvimento da grande indústria. Ou seja, a especialização de parte da sociedade em produtores mundiais de manufaturas supôs a disponibilidade de outra parte na especialização direta de produtos primários, o que conduziu em termos de transação comercial entre nações a uma "transgressão internacional nas relações de troca" (MARINI, 2012, p. 144). Segundo o autor, o fato de que as primeiras produzam bens que os países satélites não o façam, ou não o façam com o mesmo desenvolvimento tecnológico, permite que iludam a lei do valor, vendendo seus produtos a preços superiores a seu valor real, configurando uma troca desigual.

A partir deste condicionante os países centrais não apenas constituíram as condições necessárias para um forte incremento e massificação da classe operária industrial, divorciada do campo e livre para a indústria; mas também a combinação entre o aumento da capacidade produtiva do trabalho e a redução do valor gasto na reprodução física do trabalhador. É justamente sob este último aspecto que se apresenta o "caráter contraditório na dependência latino-americana" (MARINI, 2012, p. 138). A inserção subsidiária dos países latino-americanos impulsionou uma mudança qualitativa na composição-valor do capital: a transição da mais-valia absoluta à maisvalia relativa nas economias centrais. Em detrimento, o que se verificou para estes foi um efeito reverso: a 
produção - seja de exclusivos bens primários ou mesmo em sua industrialização tardia ao início do século XX - se constituiu, fundamentalmente, com base em uma superexploração do trabalhador (MARINI, 2012, p. 147).

Temos que a incidência latino-americana afetou diretamente a taxa de mais-valia desse operariado urbano a partir da variação das suas partes componentes - o trabalho necessário e o trabalho excedente reduzindo os custos do primeiro através da desvalorização dos bens-salário ${ }^{1}$. De outra forma, podemos compreender este fenômeno em Marx (2011) sob o seguinte raciocínio: quando o comércio exterior barateia os elementos do capital constante ou os meios de subsistência de primeira necessidade em que é investido o capital variável, contribui para que aumente a taxa de lucro, ao elevar a taxa de mais-valia e reduzir o valor do capital constante. Tem-se assim, que a dependência latino-americana atua como fator de compensação da taxa de lucro dos países centrais. Pois, mediante a exportação de produtos abaixo do seu valor real, este continente intensifica a produtividade da grande indústria e contribui para contrarrestar a natureza contraditória da acumulação do capital em seu processo de expansão. O que se apresenta aqui é a reprodução de relações econômicas que perpetuam e amplificam o atraso e cuja posição desvantajosa dos países dependentes no mercado internacional é o próprio fator responsável pela sua deterioração econômica, "isso implica que as nações desfavorecidas devem ceder gratuitamente parte do valor que produzem, e que essa cessão ou transferência seja acentuada em favor daquele país que lhes venda mercadorias a um preço de produção mais baixo." (MARINI, 2011, p. 145).

A esta transferência dual de valor, Florestan Fernandes (2009, p. 62) a classifica como uma "sobreapropriação repartida do excedente econômico", cuja extração de mais-valia é duplamente intensificada, com fins de atender a burguesia nacional e internacional. Aqui a debilidade econômica para fora supõe uma rigidez das relações entre classes para dentro das economias latino-americanas em nítido desfavorecimento aos trabalhadores, e cuja expressão mais latente é a "forte depressão relativa na remuneração do trabalho." (FERNANDES, 2009, p. 66). Logo, o problema da dependência para a burguesia da periferia capitalista jamais apresenta como alternativa a ruptura com a troca desigual. Mas, na compensação da perda da mais-valia por meio de uma maior exploração do trabalhador a nível de produção interna, desonerando a si dos custos do subdesenvolvimento.

Este mecanismo de compensação vai ficar conhecido nas obras de Marini $(2011,2012)$ como a já mencionada superexploração do trabalho, a qual pode ser compreendida pela combinação do uso extensivo e intensivo da força-de-trabalho pelo capital. Sob esse ângulo, podemos descrevê-la a partir de três mecanismos: o primeiro é o aumento da intensidade do trabalho, obtido através de uma maior exploração do trabalhador. $\mathrm{O}$ segundo procedimento é a conhecida extensão da jornada de trabalho, com a máxima apropriação do tempo de trabalho excedente pelo capitalista (a forma clássica da mais-valia absoluta). Nestes dois primeiros casos, tem-se como aspecto central um dispêndio de força-de-trabalho superior à média, ocasionando o esgotamento físico precoce do operário. Já o terceiro mecanismo caracteriza-se pela redução do consumo do trabalhador, cujo salário consiste numa remuneração abaixo do estritamente indispensável à sua subsistência: o nosso crônico arroxo salarial.

Contradizendo o pensamento desenvolvimentista, o qual pressupunha ser o subdesenvolvimento uma fatalidade originária do atraso capitalista no continente e cujo remédio estaria posto na industrialização da periferia, o que a história vai nos apresentar é que a industrialização nos países periféricos se deu em sentido muito distinto da sua configuração nos países centrais e nunca decorreu entre nós qualquer insuficiência ou limitações de ordem pré-capitalista. Ao contrário, trata-se de um capitalismo peculiar, cuja subordinação econômica - da fase colonial ao período monopolista - se dá para assegurar a reprodução ampliada do capital internacional. O que pretendemos afirmar é ser o subdesenvolvimento a própria expressão político-econômica e cultural da dependência, sendo a sua superação apenas possível através da própria supressão das relações sociais capitalistas que o determinam. Assim, concordamos com Fernandes (2009, p. 86-87) sobre o grande dilema do padrão conservador da modernização latino-americana, o qual supôs formas de crescimento deformadas e perpetuadoras do subdesenvolvimento, onde, ao exemplo da industrialização, tendeu "a criar economias, sociedades e culturas homólogas aos modelos originais, mas para funcionar sob o seu controle indireto, sob a sua influência e para o seu proveito". Isto é, tratou aqui de modelos similares, mas usurpados no essencial: no caráter autônomo e autossustentado da economia.

Desta forma, em países como o Brasil, o rebaixamento do considerado estritamente necessário à reprodução física da força-de-trabalho não permitiu o nascimento de uma indústria nacional voltada à produção de bens manufaturados de consumo popular, como se sucedeu nos países industriais clássicos ${ }^{2}$. Se a emergência da sua indústria esteve condicionada às crises internacionais, no fenômeno conhecido pela política de substituição de importações $^{3}$, quando fatores externos restringiram o acesso da esfera alta de consumo para a importação de bens supérfluos; a sua possibilidade concreta tornou-se viável através do excedente oriundo da superexploração do trabalhador, passível de ser capitalizado em novos nichos de produção nacional. Segundo Marini, 
[...] a economia industrial dependente reproduz, de forma específica, a acumulação de capital baseada na superexploração do trabalhador. Em consequência, reproduz também o modo de circulação que corresponde a esse tipo de acumulação, ainda que de maneira modificada: já não é a dissociação entre a produção e a circulação de mercadorias em função do mercado mundial o que opera, mas a separação entre a esfera alta e a esfera baixa da circulação no interior mesmo da economia, separação que, ao não ser contraposta pelos fatores que atuam na economia capitalista clássica, adquire um caráter muito mais radical. (MARINI, 2011, p. 164).

A produção latino-americana é o reflexo do seu abismo entre classes. Ela nasce dissociada das demandas salariais dos trabalhadores e atende, sobretudo, as necessidades modernas de consumo dos setores nãoprodutivos. No que diz respeito aos trabalhadores, a esses coube o papel de ofertar uma grande disponibilidade de força-de-trabalho a baixo custo. Todavia, a economia dependente em sua fase industrial não se caracteriza apenas pela parca remuneração aos de baixo, mas por outro fenômeno de importância não-desprezível: o aumento da produtividade através do recurso à tecnologia estrangeira. É nesta segunda característica que se apresentam novas dinâmicas e contradições à relação centro/periferia.

À medida que se consolida a industrialização na periferia altera-se o conteúdo da troca com os países centrais, acentuando o seu caráter desigual. Diante das dificuldades de valorização do montante de excedentes acumulados pelos grupos monopolistas, e saturado o espaço capitalista de inversões, tais difículdades são contornadas através da migração dos capitais excedentes por cima de fronteiras nacionais. Daí que a periferia se torna um espaço estratégico para o investimento dos superlucros dos monopólios.

Segundo Fernandes (1976), tal dinâmica é inerente à fase contemporânea e mais madura da dominação externa: o imperialismo total ${ }^{4}$. Neste estágio o imperialismo organiza a dominação a partir de dentro e em todos os níveis da ordem social - desde a educação, comunicação e consumo, até a transferência de tecnologias e instituições sociais, os expedientes financeiros e a interferência nas decisões da política nacional - ocupando todos os interstícios da vida social. Tanto os interesses privados externos, os grandes monopólios e as superpotências capitalistas, quanto os internos - a suposta burguesia nativa - estão empenhados na exploração do subdesenvolvimento. Esta forma de ingerência se apropria das posições de liderança antes ocupadas pelas empresas nacionais através de mecanismos financeiros, associação com sócios locais, corrupção, pressão e outros meios, com vistas aos interesses das empresas corporativas.

Podemos sistematizar em três pontos a dependência nesta nova fase. Primeiro, a constatação de um moderno mercado capitalista de autonomia restrita, cuja ingerência externa é compartilhada entre algumas nações, com destaque aos Estados Unidos. Em segundo, a ausência de requisitos fundamentais ao desenvolvimento econômico e sociocultural das nações latino-americanas, até mesmo entre aquelas de economia mais avançada. Como antes, tais requisitos são cedidos conforme os interesses e disposição estrangeira, a exemplo da transplantação de tecnologias, instituições, controle financeiro e suprimento externo de capital ${ }^{5}$. Considerando que a dependência apenas se efetiva com a coexistência e legitimidade de dentro das economias satélites, por último aspecto, temos que essa forma de dominação reafirma o caráter altamente particularista da burguesia latino-americana, cujos interesses mantêm-se simbióticos à exploração do subdesenvolvimento e vinculam-se organicamente ao imperialismo internacional.

Logo, o mundo subdesenvolvido posto à luz do modelo original - civilizado, ocidental e moderno aparenta ter carências, incompletudes ou, como mais comumente pensado, estar num estágio transitório da evolução capitalista, visto na famosa retórica aos países em desenvolvimento. Contudo, encarado o fenômeno tal como se apresenta, o que temos é que em países como o Brasil, a Revolução Burguesa deu-se sob o impacto da crônica perda aos de baixo, onde a limitada autonomia obtida acanhou-se em benefício dos setores privilegiados, dando origem ao que Florestan Fernandes (1976) nomeou por ser um capitalismo dificil.

\section{A cultura autocrática}

O que denominamos por cultura autocrática é próprio da necessidade de autoprivilegiamento e autoproteção burguesa que, em nome da estabilidade política, estatiza a violência sistemática contra os de baixo, ultrapassando os limites do seu braço armado e a condensando nas políticas sociais e demais esferas públicas de interlocução com os trabalhadores. Prova disto é a ressignificação de direitos fundamentais e a flexibilização de princípios constitucionais, reinterpretados segundo a ótica de antigas mistificações como a proteção do regime democrático ou a defesa da ordem. Se formos à raiz deste fenômeno verificamos que a sua validade é fundada em dois aspectos de nossa contemporaneidade: a manutenção da dependência e a reciclagem do período contrarrevolucionário. Em síntese, é este um fenômeno político simbiótico e prerrogativa necessária à dependência. 
A fim de compreender o primeiro elemento condicionante - a manutenção da dependência - se faz necessário o olhar sobre o Brasil contemporâneo. Como nos demais países latino-americanos, o Brasil também sofre os impactos de reorientação econômica advindos da nova divisão internacional do trabalho. De economia urbano-industrial, a América Latina vem se constituindo nas três últimas décadas em uma grande economia agroexportadora. Cresce em relevância e concentração de capitais os setores monopolizados pela soja, cana-de-açúcar, agropecuária e siderurgia sobre o setor industrial, na mesma proporção em que se verifica o crescimento do setor industrial de produtos primários: os chamados bens semimanufaturados.

Matérias-primas processadas para exportação - com destaque aos produtos petroquímicos, ferro, aço, celulose, papel, alumínio, minerais, laranja e pescado - apresentam elevadas taxas de investimento, em muito superiores às dos ramos industrias dedicados à produção de bens supérfluos ou de capital fixo. Ainda que a noção de manufaturas baseadas em recursos naturais conduza muitas vezes ao equívoco de se equalizar este processo à industrialização propriamente dita, o que se vislumbra são pontuais intervenções manufatureiras sobre a base primária das mercadorias, como o enlatado de alimentos vegetais, carnes ou o engarrafado de sucos e vinhos. A produção industrial propriamente dita limita-se, em geral, ao setor de montagem automotiva, peças de eletrônica e confecção de artigos de luxo.

O que importa identificar na originalidade do acontecimento é o modo pelo qual as transformações do sistema de produção encadeiam a manutenção de estruturas herdadas do passado com a formação de estruturas socioeconômicas novas. E é assim, nesta perspectiva heterônoma, que se constitui a retomada em grande escala do caráter primário da periferia capitalista, cujos velhos signos da dependência e do subdesenvolvimento mantêm-se preservados em novos patamares de contradição.

Perdendo apenas para Ásia - com destaque à China

Ao afirmarmos a existência de uma cultura autocrática supomos algo inevitável diante dos fatos históricos: a superação da natureza autocrática do Estado não se realizou, ato que exigiria muito de nossa burguesia nacional. e à Índia - a América Latina é hoje o segundo maior continente exportador. Entretanto, o que a princípio poderia ser interpretado enquanto um fenômeno positivo, o dito $c r e s c i$ mento da economia latino-americana detém características em nada favoráveis ao seu hipotético desenvolvimento. A economia centrada na exportação de commodities, responsável por suprir em matérias-primas e alimentos as necessidades do mercado internacional, tem por seu reverso um crescimento ascendente da importação de mercadorias. Produtos industrializados, bens de capital e tecnologia, muitos dos quais antes produzidos a nível local, são importados para suprir as necessidades do mercado interno e reatualizam, neste velho ciclo, um fenômeno em nada inédito: o crônico saldo negativo da balança comercial. Em consequência, o custo desta disparidade advém tanto da dependência ao afluxo de capitais especulativos estrangeiros que cubram este déficit e permitam um artificial equilíbrio nas contas de cada país; como na sangria de riquezas dirigida ao bolso do capital especulativo internacional através das indecentes taxas de juros pagas ${ }^{6}$.

Todavia, a ingerência externa não se limita apenas à sujeição ao capital especulativo, ela faz-se presente em todo o processo de realização da economia. Na geração e distribuição de energia, nos serviços de telefonia e transporte, na produção de insumos energéticos, de alimentos e semimanufaturados de recursos naturais, ampliou-se significativamente o quantitativo de fusões entre empresas internacionais, bancos e grandes conglomerados locais. A privatização de serviços públicos - a exemplo da energia elétrica, a administração portuária e a rodoferroviária - tornou-se um espaço em potencial para supercapitalização transnacional ${ }^{7}$. Assim, se a qualidade da riqueza produzida se constitui em detrimento dos anseios internos, diluem-se crescentemente as fronteiras entre o supostamente nacional e os limites de fora.

Com um significativo incremento no valor das exportações via produção de commodities, identifica-se a maior participação dos produtos básicos em detrimento dos manufaturados. Por exemplo, se tomarmos como referência os dados da Associação de Comércio Exterior do Brasil (AEB, 2012, p. 11), o total de exportações realizadas no ano de 1985, 33,3\% diziam respeito a produtos básicos, 10,75\% a bens semimanufaturados e $54,85 \%$ a produtos industriais. Em 2012, a exportação de produtos básicos atingiu o percentual de 45,5\%, os semimanufaturados $13,93 \%$, enquanto as mercadorias industriais apenas $38,4 \%$ do total das exportações. Se constatamos que a década de 1990 demonstrou indicativos das possíveis alterações na prioridade da base produtiva do país, é no giro ao século XXI que se reatualiza a sua face primária. Enquanto nos anos de 1995 a 2000 os produtos básicos atingiram o percentual médio de 22,7\% das exportações, em 2011 e 2012 esse 
percentual é duplicado ${ }^{8}$ Em paralelo, é significativa a redução da exportação de bens industrializados nos últimos dez anos, aproximando-nos de um perfil econômico ao do ano de $1978^{9}$.

Desta forma, as commodities são hoje responsáveis por mais de $80 \%$ dos volumes quantitativos (em milhões de toneladas) das exportações no país, destacando-se por ordem de relevância, a exportação de soja em grão, petróleo, açúcar bruto, farelo de soja, celulose, açúcar refinado, agropecuária e suco de laranja; ao que segue em índice reduzido - inferior a $10 \%$ do valor das exportações - a produção de mercadorias industriais: aeronaves, veículos automotores e partes de veículos. Longe de representar um papel coadjuvante, as commodities encontram-se no centro da economia brasileira, cujas receitas ultrapassam o percentual de $70 \%$ da comercialização internacional ${ }^{10}$.

Segundo avaliação do Ministério do Desenvolvimento, Indústria e Comércio Exterior (MDIC) (AEB, 2012, p. 7), o decênio 2001-2011 representou para as commodities impressionantes índices percentuais de crescimento, cujas magnitudes são praticamente impossíveis de serem projetadas em qualquer outro cenário. Tal fato pode ser visto no crescimento das receitas oriundas da exportação do petróleo (aumento de 13,572\%), açúcar bruto $(1,417 \%)$, minério de ferro $(1,271 \%)$, carne de frango $(776 \%)$, açúcar refinado $(674 \%)$, carne bovina $(729 \%)$ e soja (646\%). Cabe destacar que apenas quatro commodities - minério de ferro, petróleo, soja em grão e açúcar bruto - foram responsáveis por 35\% das exportações.

Entretanto, a redução dos produtos manufaturados na pauta das exportações brasileiras impulsiona, em sentido contrário, a sua maior presença nas importações. Não é por menos que no período de 2000-2011 a importação de manufaturas cresceu em 100\%, sendo apenas a de bens industrializados responsável por 79,5\% do total no período. Outro dado interessante é o destino e origem da exportação/importação das mercadorias (AEB, 2012, p. 9-10).

Segundo a AEB (2012, p. 13), no período 2000-2011 as exportações totais do Brasil cresceram 365\%, tendo por principais mercados consumidores, respectivamente, China, Estados Unidos, Argentina, Holanda, Japão e Alemanha. Entretanto, apenas algumas economias evidenciaram indicadores exponenciais de crescimento na importação de produtores brasileiros, com notoriedade para a China com um aumento de 3,984\%; para a Índia em 1,374\%; e para a Coréia do Sul em 709\%. O que esta relação entre nações nos demonstra é a atualidade do que Marini (2011) afirmava ser o caráter próprio ao modelo subordinado da periferia latinoamericana: a função de atender uma oferta mundial de alimentos e matérias-primas, cuja relevância é proporcional às necessidades da grande indústria. Em um momento histórico de transnacionalização e desterritorialização da produção, controlada acima das fronteiras de Estados e nações, é substantivo ter a China na condição de maior país consumidor das exportações brasileiras, ao que sucede uma presença cada vez mais significativa das novas nações industriais. O sentido aqui mantém-se intacto: a qualidade das exportações brasileiras são subsidiárias às necessidades de reprodução do capital, seja na condição de insumo energético ou de artigos de primeira necessidade.

A partir do exposto, podemos compactuar com a assertiva sobre a qual o processo histórico brasileiro é sempre não-contemporâneo. As bases materiais que moldam a face atual deste país através da reprimarização da economia são compatíveis, numa mesma estreiteza e desfavorabilidade interna, ao que Chasin (2000, p. 56) nomeou por ser o nosso "capitalismo verdadeiro" ou "capitalismo híper-tardio brasileiro". Reatualiza-se sob novos indicadores os mecanismos de superexploração, cuja resultante é a deterioração das condições laborais e de vida dos trabalhadores, bem como a perda do poder aquisitivo dos salários na dinâmica do mercado interno. As commodities e os bens manufaturados aqui produzidos, ao serem apartados das necessidades das grandes maiorias, resultam apenas na intensificação da tendência de sua pauperização relativa.

Esta intensificação pode ser facilmente verificável nas taxas de mais-valia extraídas. Ao contrário dos níveis prevalecentes nas economias centrais, a tendência de exploração da força-de-trabalho no Brasil mantém-se elevada até a primeira metade dos anos 2000: entre 1995 e 2004, a taxa de mais-valia cresce $2,8 \%$ ao ano, passando do nível de 1,62 a $2,06 \%$ e, após 2004 , a taxa se estabiliza em torno de $1,97 \%$ (ARAÚJO, 2011, p. 154). Já no que diz respeito ao salário mínimo, este é hoje quatro vezes menor do que o necessário ao sustento do trabalhador e de sua família ${ }^{11}$. Segundo Araújo, "podemos afirmar que, grosso modo, o padrão histórico de exploração da força de trabalho no Brasil se manteve praticamente inalterado na fase atual do capitalismo, assinalada pelo prolongamento da crise estrutural e pelo predomínio das políticas neoliberais." (ARAÚJO, 2011, p. 155). Diante do contexto recessivo para o trabalho, não apenas as contratendências ratificam o seu caráter estrutural às economias dependentes ${ }^{12}$, como são intensificadas em períodos de crise, haja vista a tramitação da contrarreforma da previdência e a aprovação da contrarreforma trabalhista, cujas mudanças apresentadas preveem desde agravantes como a flexibilização da jornada de trabalho, liberação irrestrita da terceirização e o trabalho intermitente à possibilidade de grávidas trabalharem em locais insalubres. 
Nesta perspectiva, o segundo elemento estruturante à cultura autocrática - a reciclagem do periodo contrarrevolucionário - é fenômeno político indispensável ao controle da força-de-trabalho e à consequente preservação da superexploração.

O regime autocrático tal como o conhecemos - enquanto poder autointitulado de classe, que converte "o Estado nacional e democrático em instrumento puro e simples de uma ditadura de classe preventiva" (FERNANDES, 1976, p. 297) - consiste em uma saída política temporária, dado os limites de manutenção de uma ordem autoreferenciada apenas no estrito campo de interesses burgueses. Mas, como bem sinaliza Iasi (2012, p. 303), a peculiaridade que aqui se apresenta são as características estruturais de nossa formação sóciohistórica que acabam por impor à autocracia burguesa uma longevidade muito além do que a sua forma transitória. A alta concentração de riqueza e poder não poderia ser um critério seguro o suficiente para proporcionar estabilidade à condição burguesa, ao passo que os não-classificados ou que se classificam parcialmente são muito grandes. Desta forma, o desafio que circundou a burguesia ao fim do seu ciclo contrarrevolucionário era o de como legitimar-se a partir de canais de consenso sem, todavia, alterar a rígida estratificação entre classes sociais.

Fernandes (1976), ao fim da obra A Revolução Burguesa no Brasil, questionando-se ao findar da primeira metade da década de 1970 se o que vivíamos seria uma persistência ou colapso da autocracia, desenvolve um conceito analítico chave para refletir sobre o seu presente, ao que denominou por democracia de cooptação ${ }^{13}$. Para o sociólogo, o que as classes burguesas aspiravam ao fim do seu ciclo contrarrevolucionário era a estabilização de condições para o crescimento da ordem social competitiva, de forma a manter suas vantagens e privilégios sem abrir mão do controle que dispunham sobre seu status político e material, sobre a classe trabalhadora e as bases da superestrutura estatal. A fim de realizar tal feito, impôs-se à classe dominante reciclar "os mecanismos rotineiros de dominação de classe direta ou mediada, por novos controles formais e, especialmente, por controles coercitivos de caráter estatal” (FERNANDES, 1976, p. 364):

E aqui está o busílis da questão. Essa articulação política entre os mais iguais, democrático-oligárquica em sua essência e em suas aplicações assume, de imediato e irremediavelmente, a forma de uma cooptação sistemática e generalizada. A cooptação se dá sempre implicando a mesma coisa: a corrupção intrínseca e inevitável do sistema de poder resultante. [...] Desse ângulo, a autocracia burguesa leva a uma democracia restrita típica, que se poderia designar como uma democracia de cooptação. (FERNANDES, 1976, p. 358, grifos nossos).

Compactuando com a análise apresentada pelo autor, podemos afirmar que os esforços de distensão política, realizados pelas classes burguesas dentro dos marcos da defesa da Revolução Burguesa e do seu tempo econômico ofereceriam os contornos necessários para a estabilidade da democracia de cooptação, através de um duplo dinamismo: da institucionalização do poder político excedente, instrumentalizado constitucional e legalmente em certas funções ditatoriais permanentes do Estado democrático e constitucional; e, através da abertura da cooptação para baixo, para a "dissidência esterilizada e esterilizável dos setores insurgentes" (FERNANDES, 1976, p. 358). Levado a cabo a sua morna transição democrática, a burguesia brasileira não se autocondenou a uma contrarrevolução permanente. Entretanto, nos deixou como legado uma cultura autocrática a nível econômico, político e social, intrínseca à inserção subalterna na divisão internacional do trabalho, da qual a democracia de cooptação como meio de gestão política do Estado e a sua respectiva "corrupção intrínseca e inevitável do sistema de poder resultante" (FERNANDES, 1976, p. 358), que lhe é um dos elementos mais destacados ${ }^{14}$.

Ao afirmarmos a existência de uma cultura autocrática supomos algo inevitável diante dos fatos históricos: a superação da natureza autocrática do Estado não se realizou, ato que exigiria muito de nossa burguesia nacional. Para "vencer esta circularidade histórica, elas careciam de um excedente de poder bem diverso, que não lhes desse apenas autonomia de classe para 'dentro', mas também autonomia de classe para 'fora', que servisse de substrato para uma ruptura imperialista." (FERNANDES, 1976, p. 353). O que se apresenta aqui é a nossa peculiaridade: uma democracia e cidadania de essência flexível, facilmente enrijecidas. A flexibilidade desta democracia detém o seu limite no cerne da dependência, quando o escasso excedente destinado ao consenso entre classes demonstra-se insuficiente. Podemos citar dois fenômenos aqui implicados: no momento em que a ação da classe trabalhadora expressa um caráter autônomo e não cooptável, cujas requisições confrontam-se diretamente com a sua condição de superexplorada. Ou, em períodos de crise cíclica do capital, quando a burguesia demanda uma maior apropriação de mais-valia e, consequentemente, também do fundo público, inviabilizando concessões aos de baixo e tornando descartáveis as alianças com setores colaboracionistas dos trabalhadores. Neste último caso, as contratendências à queda da taxa de lucro incidem sobre os direitos sociais e ameaçam até mesmo a permanência de escassas garantias, abrindo flanco a possibilidade de emergência de segmentos mais conservadores no poder do Estado e excluindo-se a necessidade da compra de alianças e lealdades, dado o exemplo histórico do Partido dos Trabalhadores (PT) e o golpe jurídico-parlamentar em 2016. 
O fato das classes sociais, em especial a trabalhadora, não terem constituído uma ruptura profunda com a contrarrevolução burguesa, mas apenas um pacto democrático ao seu fim, conduziu não à erradicação desta contrarrevolução, mas à sua diluição na sociedade civil. O que esta diluição resulta é numa curiosa contradição: a transitoriedade dos setores ultraconservadores da burguesia do monopólio do poder do Estado, mas a preservação de sua expressão econômica, política e social como diretriz para as relações entre as classes. Não é por menos que escrevemos hoje sobre um país subdesenvolvido e profundamente desigual, que se mantém reproduzindo os traços típicos de sua histórica heteronomia, a exemplo da presença de trabalho em condição análoga ao escravo e de relações de trabalho semilivres; de uma força policial altamente militarizada; do genocídio étnico da juventude negra; dos consideráveis índices de feminicídio ${ }^{15}$; de práticas patrimonialistas; e ao fim, da manutenção da estrutura latifundiária e agroexportadora aliada à presença democrática de aberrações como a bancada parlamentar ruralista ou a bancada parlamentar evangélica.

O contraponto nacional aceitável à hegemonia burguesa é somente plausível desde que tutelado e domesticado, onde possíveis posturas irreconciliáveis de segmentos dos trabalhadores sejam facilmente neutralizadas ou apartadas, tudo isto nos marcos de um pseudo Estado Democrático de Direito. Diante de uma real ameaça de classe e não sendo possível a cooptação e institucionalização das lutas sociais em seu viés colaboracionista, o que se passa aos nossos olhos é uma intensa judicialização das relações sociais. Esta cooptação da esfera jurídica opera sob a mais perversa criminalização da pobreza e dos movimentos sociais, atribuindo legalidade à violência armada do Estado e a violação sistemática de direitos civis, políticos e, sobretudo, sociais. Em sua estrutura, reatualiza o modus operandi do período contrarrevolucionário nos seus dois traços característicos: o caráter antissocial e antinacional.

Antissocial com referência a "expropriação do trabalho, à exportação do excedente econômico, à intensificação das desigualdades econômicas e, por consequência, o agravamento das tensões sociais" (FERNANDES, 2011, p. 162). No que diz respeito ao caráter antinacional - enquanto a restrição e até mesmo a negação aos setores populares do usufruto de um patrimônio político e sociocultural comum - podemos resumir em duas as suas ações, as quais possuem um impacto político complementar: a primeira é a tentativa de neutralização das vanguardas da classe trabalhadora, sobretudo, as representativas dos seus instrumentos organizativos clássicos (partidos e sindicatos); e, caso não sendo possível a cooptação, a ofensiva contra os seus segmentos mais radicais. O que detemos neste ponto é a explicitação da alternativa oferecida pelas classes dominantes aos movimentos sociais na sua relação com a sociedade política: ou sua incorporação pacífica e domesticada ou a mais completa violência e exclusão. Já a segunda característica deste modelo antinacional está no privilégio exclusivo dos interesses privatistas, cuja capacidade em atender às demandas dos trabalhadores dá-se prioritariamente com auxílio e vantagem ao capital privado. Fato este evidente na égide de contrarreformas vivenciadas nas duas últimas décadas e agora aprofundadas, enquanto ameaças ao caráter mais irrisório das garantias sociais fundamentais.

\section{Considerações finais}

Frente ao padrão de sociabilidade ora exposto - marcado pelo recrudescimento das relações de dependência e uma rígida e estratificada relação entre classes sociais - ainda é objeto de maiores surpresas tanto o golpe jurídico-parlamentar protagonizado pelo bloco de composição burguesa no ano de 2016, como os seus resultados avassaladores aos trabalhadores e às instâncias democráticas do país. A agilidade para tal feito, a respectiva unidade burguesa que o conduziu e a onda conservadora que propiciou a sua adesão e aceitabilidade (e que demonstra maior vitalidade a cada dia), não poderiam ter se efetivado sem um detalhe que o antecede: a política de colaboração entre classes perpetrada nos últimos anos pelo governo do Partido dos Trabalhadores (2003-2016).

Neste caso, a trajetória socialista e a base popular que compunham este partido não seriam elementos suficientes para fazer frente aos limites do Estado e reparar as intocadas contradições da formação sóciohistórica brasileira. Ao contrário, optou-se por preservar o essencial: as relações de dependência econômica e os elementos antissociais e antinacionais típicos à nossa cultura autocrática. Fato que se traduziu em um forte incentivo à produção das commodities via impulso ao agronegócio; os elevados níveis de extração de mais-valia; a privatização de setores estratégicos da economia e a cooptação dos movimentos sociais e o apassivamento da consciência de classe. Ainda que detendo resultados positivos no acesso ao consumo e trabalho formal dos extratos sociais mais pauperizado ${ }^{16}$ da classe trabalhadora, a estrutura político-econômica da dependência manteve-se inalterada.

Sendo assim, se afirmamos no decorrer deste ensaio que não constituímos uma ruptura com a contrarrevolução burguesa, mas apenas um pacto democrático ao seu fim, mantendo-se preservados os 
elementos estruturantes de seu viés autocrático, o que vislumbramos hoje é a bem-sucedida reivindicação dos setores ultraconservadores da burguesia ao lugar que sempre identificaram como seu - o monopólio do poder do Estado, trazendo a nu, sem qualquer constrangimento, o sentido da superexploração da força-detrabalho ao cotidiano dos de baixo.

\section{Referências}

ASSOCIAÇÃO DE COMÉRCIO EXTERIOR DO BRASIL. Radiografia do comércio exterior brasileiro: passado, presente e futuro. Rio de Janeiro: AEB, 2012.

ANTUNES, J. O fenômeno da desindustrialização latino-americana. In: SIMPÓSIO LUTAS SOCIAIS NA AMÉRICA LATINA, 3., 2008, Londrina. Anais eletrônicos... Londrina: GEPAL, 2008. Disponível em: <http://www.uel.br/grupo-pesquisa/gepal/terceirosimposio/ jadirantunes.pdf>. Acesso em: 30 mar. 2017.

ARAÚJO, E. S. As condições de exploração da força de trabalho no Brasil na fase atual do capitalismo: uma análise do período 1990 2007. 2011. 199f. Tese (Doutorado em Políticas Públicas) - Universidade Federal do Maranhão, São Luís, 2011.

BENAVENTE, J. M. et al. Nuevos problemas y oportunidades para el desarrollo industrial de América Latina. Santiago: CEPAL, 1997. CHASIN, J. A Miséria Brasileira. 1964-1994: do Golpe Militar à Crise Social. São Paulo: Ad Hominem, 2000.

DEPARTAMENTO INTERSINDICAL DE ESTATÍSTICAS E ESTUDOS SOCIOECONÔMICOS. Pesquisa nacional da Cesta Básica de Alimentos. 2017. Disponível em: <http://www.dieese.org.br/analisecestabasica/salarioMinimo.html>. Acesso em: 14 jun. 2017.

FERNANDES, F. Capitalismo Dependente e Classes Sociais na América Latina. São Paulo: Global Editora, 2009.

. A Revolução Burguesa no Brasil: ensaio de interpretação sociológica. 2. ed. Rio de Janeiro: Editora Guanabara, 1976.

. Revolução ou Contrarrevolução? In:

UFRJ, 2011. p. 157-177.

. Sociedade de classes e subdesenvolvimento. São Paulo: Global, 2008.

IASI, M. L. Democracia de cooptação e o apassivamento da classe trabalhadora. In: SALVADOR, E. et al. (Org.). Financeirização, fundo público e política social. São Paulo: Cortez, 2012. p. 285-317.

MARINI, R. M. Dialética da Dependência. In: STEDILE, J. P.; TRASPADINI, R. (Org.). Ruy Mauro Marini: Vida e Obra. São Paulo: Expressão Popular, 2011.p. 137-180.

. Subdesenvolvimento e Revolução. Florianópolis: Insular, 2012.

MARQUES, M. G. Em busca da revolução brasileira: uma análise crítica da estratégia democrático-popular. Curitiba: Prismas, 2015. MARTELLO, A. Brasil reassume liderança em ranking mundial de juros reais. G1, Rio de Janeiro, 4 mar. 2015. Disponível em: $<$ http:/ /g1.globo.com/economia/noticia/2015/03/brasil-reassume-lideranca-em-ranking-mundial-de-juros-reais.html>. Acesso em: 30 mar. 2017. MARX, K. O Capital: crítica da economia política. Livro 1: O processo de produção do capital. Rio de Janeiro: Civilização Brasileira, 2011. $2 \mathrm{v}$.

NETTO, J. P; BRAZ, M. Economia Política: uma introdução crítica. 8. ed. São Paulo: Cortez, 2012.

OSORIO, J. El nuevo patrón exportador de especialización productiva en América Latina. Revista Sociedade Brasileira de Economia Política, São Paulo, n. 31, p. 31-64, fev. 2012.

POCHMANN, M. Nova Classe Média? O trabalho na base da pirâmide social brasileira. São Paulo: Boitempo, 2012.

PRADO JÚNIOR, C. Formação do Brasil Contemporâneo. São Paulo: Companhia das Letras, 2011.

. História Econômica do Brasil. São Paulo: Brasiliense, 1970.

WAISELFISZ, J. J. Mapa da Violência 2013: homicídios e juventude no Brasil. Brasília, DF: Secretaria Geral da Presidência da República, 2013. Disponível em: <http://www.mapadaviolencia.org.br/pdf2013/mapa2013_homicidios_juventude.pdf>. Acesso em: 30 mar. 2017.

\section{Notas}

1 Segundo Marini (2011), a manutenção da população urbana ocupada na indústria e nos serviços no século XVIII não poderia ter acontecido se esses não dispusessem de meios de subsistência de origem agropecuária e agrícola fornecidos de forma considerável pelos países latino-americanos. A exemplo, a importação de alimentos pela Inglaterra até 1880 era de “ $45 \%$ para o trigo, $53 \%$ para a manteiga e o queijo, $94 \%$ para as batatas e $70 \%$ para a carne" (MULHALL apud MARINI, 2011, p. 140).

2 Nas economias centrais há um fato distintivo: a emergência da sua indústria concentrou-se, fundamentalmente, nos bens manufaturados de consumo popular e, em menor medida, na produção de artigos supérfluos ou nos bens de capital, como máquinas e tecnologia para a indústria pesada.

3 Dentre as circunstâncias que fomentaram o avanço da industrialização brasileira a partir da política substitutiva de importações nos anos 19301950, Prado Jr. (1970, p. 258) destaca três: em primeiro lugar, a "dificuldade do país de pagar no estrangeiro as manufaturas necessárias ao seu consumo", o que se expressou num contínuo declínio do câmbio monetário e no encarecimento das mercadorias de importação. Em segundo, a “elevação progressiva das tarifas alfandegárias". A política tarifária - privilegiando interesses financeiros e não uma proteção específica à indústria 
nacional - onerou indiscriminadamente tanto os gêneros da sua produção, como indireta ou diretamente, os seus artigos subsidiários. Em terceiro lugar, a disposição favorável do algodão, enquanto matéria-prima de grande importância para parte substancial das primeiras maquinofaturas no país - a indústria têxtil. E, por fim, e não menos importante, "a grande disposição de força-de-trabalho".

4 Antecede o imperialismo total três formas de dominação: o sistema colonial, neocolonial e o imperialismo restrito. Para maiores informações cf. Fernandes (2009, p. 21-41).

5 Segundo Marini (2011, p. 167), na medida em que o progresso técnico "reduziu nos países centrais o prazo de reposição do capital fixo praticamente à metade, colocou-se para esses países a necessidade de exportar equipamento e maquinário que já eram obsoletos antes de que tivessem sido amortizados totalmente". Transferiu-se para a América-Latina o atraso tecnológico das nações centrais a partir de uma nova e moderna hierarquização da economia capitalista mundial.

6 O Brasil adentrou o ano de 2015 na condição de liderança do ranking mundial de juros reais. Segundo o site G1, “[...] o Brasil, após a nova alta promovida pelo Banco Central neste ano, tem juros reais de 5,28\% ao ano. Está bem acima do segundo e terceiros colocados, a China e a Índia, que possuem juros reais de 3,18\% e de 3,17\% ao ano, respectivamente. Em quarto e quinto lugares, figuram Taiwan (1,47\% ao ano) e Filipinas (0,97\% ao ano).” (MARTELLO, 2015).

7 Cf. Benavente et al. (1997).

8 No Brasil, em 1980, auge da industrialização via substituição de importações, a indústria de transformação participava com cerca de $31,3 \%$ do PIB total do país. Em 2004, esta participação caíra para 23\%, regredindo ao mesmo patamar alcançado em 1955 . Ou seja, em 14 anos, a participação relativa da indústria de transformação no PIB brasileiro diminuiu em um 1/4. Em 1950, a indústria extrativa mineral participava com cerca de $0,4 \%$ do PIB nacional. Em 2004, ela atingira a marca de 4\%. Num intervalo de 54 anos, ela cresceu, portanto, cerca de 1.000\%. A agropecuária, que participava com apenas 6,9\% em 1990, sua menor participação na história econômica do país, se recupera ano após ano e em 2004 já participava com 9,7\% do PIB nacional. Em apenas 14 anos ela cresceu cerca de $50 \%$. Entre 1990 e 2005, a produção de soja cresceu $257 \%$ e a de cana-de-açúcar 161\%. (ANTUNES, 2008, p. 7).

9 Em 1978 a exportação brasileira caracterizava-se pelo percentual de $47.22 \%$ de produtos primários, $11.22 \%$ de produtos semimanufaturados e $40.15 \%$ de manufaturados (AEB, 2012, p. 11).

10 Cf. Associação de Comércio Exterior do Brasil (AEB, 2012, p. 8) e Osorio (2012).

11 Segundo o Departamento Intersindical de Estatísticas e Estudos Socioeconômicos (DIEESE) (2017), o salário mínimo necessário para as despesas do trabalhador e de sua família deveria ser em maio de 2017 de R \$3.869,92, ao passo que esse valor mensurava em de apenas R $\$ 937,00$.

12 Segundo Netto e Braz (2012, p. 164-167), as contratendências configuram-se como meios para reverter a tendência à queda da taxa de lucro o barateamento do capital constante; a elevação da intensidade da exploração (através do incremento de mais-valia absoluta e/ou relativa); a depressão dos salários abaixo do seu valor; o exército industrial de reserva e o comércio exterior (o qual conduz os países desenvolvidos aos superlucros sob vantagens especiais).

13 Sobre o desenvolvimento do conceito democracia de cooptação, conferir também Iasi (2012).

14 Cf. Marques (2015, p. 178-221).

15 Dados do Mapa da Violência (WAISELFISZ, 2013) demonstram que na última década (2002-2011) foram assassinados 307.629 negros/as no país. No que diz respeito às taxas de feminicídio, os dados também seguem alarmantes. O número de homicídios femininos nas três últimas décadas (1980-2011) atingiu o número de 96.612. Contudo, apenas na última década (2000-2011) este representa quase 50\% do total.

16 Cf. Pochmann (2012).

\section{Morena Gomes Marques}

morenamarques@yahoo.com.br

Mestrado em Serviço Social pela Universidade do Estado do Rio de Janeiro (UERJ)

Professora da Escola de Serviço Social da Universidade Federal do Estado do Rio de Janeiro (UNIRIO)

\section{UNIRIO}

Avenida Pasteur, 458 - Urca

Rio de Janeiro - Rio de Janeiro - Brasil

CEP: $22.290-240$ 